\title{
Analysis of Tensile Deformation Behavior by in situ Neutron Diffraction Experiments of 1 GPa-grade TRIP Steels with High Elongation
}

\author{
Noriyuki TSUCHIDA, ${ }^{1 * *}$ Takaaki TANAKA ${ }^{2)}$ and Yuki TOJI2) \\ 1) Graduate School of Engineering, University of Hyogo, 2167 Shosha, Himeji, 671-2280 Japan. \\ 2) Steel Research Laboratory, JFE Steel Co., 1 Kawasaki-cho, Chuo-ku, Chiba, 260-0835 Japan.
}

(Received on November 19, 2019; accepted on December 13, 2019; originally published in Tetsu-toHagané, Vol. 105, 2019, No. 9, pp. 918-926)

\begin{abstract}
The better uniform elongation of the $1 \mathrm{GPa}$-grade TRIP-aided multi-phase steel with retained austenite $\left(\gamma_{R}\right)$ shape of needle-like was discussed by in situ neutron diffraction experiments during tensile test. The better uniform elongation can be ascribed by not only the deformation-induced martensitic transformation of $\gamma_{R}$ but also the deformation behavior of $\gamma_{R}$ and ferrite phase. Especially, the tensile deformation behavior of $\gamma_{R}$ is found to be closely associated with both of the stress-strain curve and the deformation-induced martensitic transformation of $\gamma_{R}$. The tensile deformation behavior of $\gamma_{R}$ should be considered as one of the conditions to obtain better TRIP effect.
\end{abstract}

KEY WORDS: TRIP; TRIP-aided multi-phase steel; neutron diffraction experiments; lattice strain; phase strain; deformation-induced martensitic transformation.

\section{Introduction}

TRIP-aided multi-phase (TRIP) steels can provide high strength and better elongation due to the transformationinduced plasticity (TRIP) effect ${ }^{1,2)}$ that results from the deformation-induced martensitic transformation of retained austenite $\left(\gamma_{R}\right)$. Mechanical properties of various TRIP steels such as those obtained from medium- and high-carbon steels, ${ }^{3-6)}$ those whose matrix microstructures are bainite or martensite ${ }^{7,8)}$ and so on, have been studied. The main application of TRIP steels is for automotive use. Automotive steels require high strength in order to reduce vehicle weight, and high-strength automotive steels with tensile strengths of 1 to $1.5 \mathrm{GPa}$ have been investigated. ${ }^{8,9)}$

In our previous study, two types of $1 \mathrm{GPa}$-grade TRIP steels with different $\gamma_{R}$ morphologies were prepared using a $0.3 \% \mathrm{C}$ steel, and the high-speed tensile deformation behavior and strain rate dependence of mechanical properties at room temperature were studied. ${ }^{10)}$ As a result, a TRIP steel with needle-like $\gamma_{R}$ morphology (needle-like $\gamma_{R}$ steel) having a tensile strength of $1 \mathrm{GPa}$ and total elongation of $40 \%$ was found and indicated better workability and collision safety. When the mechanical properties of the two TRIP steels were compared, the needle-like $\gamma_{R}$ steel indicated better uniform elongation at low strain rates below $10^{-3}$ $\mathrm{s}^{-1}$ even though the tensile strength was almost the same at about $1 \mathrm{GPa}$. However, it is necessary to clarify the reasons

* Corresponding author: E-mail: tsuchida@eng.u-hyogo.ac.jp DOI: https://doi.org/10.2355/isijinternational.ISIJINT-2019-751 for the better uniform elongation and high strength of the needle-like $\gamma_{R}$ steel by methods other than X-ray diffraction experiments which can investigate only the deformationinduced transformation behavior. ${ }^{10)}$ To resolve the issue, we conducted in situ neutron diffraction experiments during tensile deformation.

The results of neutron diffraction experiments using various steels including TRIP steels with various strength levels ${ }^{11-17)}$ have been reported. Through such experiments during tensile deformation using TRIP steels, it is possible to clarify not only lattice and phase strains which are related to intergranular and phase stresses but also the deformationinduced martensitic transformation behavior. ${ }^{11-14)}$ Furthermore, recently, it has become possible to obtain neutron diffraction profiles with high statistical precision in a short time by using a pulsed neutron facility with high beam intensity. Neutron diffraction experiments can also analyze lattice and phase strains of martensite phase which has been difficult to be analyzed to date. ${ }^{11,15)}$ That is, in situ neutron diffraction experiments can be used to determine the lattice and phase strains of not only ferrite $(\alpha)$ and austenite $(\gamma)$ phases but also the deformation-induced martensite $\left(\alpha^{\prime}\right)$ phase in TRIP steels, and so such experiments have become increasingly important for understanding the tensile deformation behavior of TRIP steels. ${ }^{11,18)}$

In this study, in situ neutron diffraction experiments during tensile deformation were conducted using $1 \mathrm{GPa}$-grade high-strength TRIP steels with different $\gamma_{R}$ morphologies. The reasons for the better uniform elongation of the needlelike $\gamma_{R}$ steel are discussed in terms of lattice strain, phase 
strain and deformation-induced martensitic transformation behavior obtained by analyses of ferrite, austenite and martensite phases.

\section{Experimental Procedures}

In this study, two types of TRIP steels with different $\gamma_{R}$ morphologies were prepared using a $0.3 \mathrm{C}-1.5 \mathrm{Si}-2 \mathrm{Mn}$ $($ mass $\%)$ steel ${ }^{10)}$ and named needle-like $\gamma_{R}$ steel and blocky $\gamma_{R}$ steel, respectively. These TRIP steels were obtained by heating to $1033-1053 \mathrm{~K}$ and were austempered at $673 \mathrm{~K}$ for $600 \mathrm{~s}$ followed by air-cooling using a cold rolled steel (blocky $\gamma_{R}$ steel) and a steel with martensite microstructure that was quenched after cold rolling (needle-like $\gamma_{R}$ steel). ${ }^{10)}$ In our previous study, ${ }^{10)}$ microstructure observations using an optical microscopy and scanning electron microscopy with electron backscatter diffraction (SEM-EBSD) and the results of static tensile tests at room temperature were reported for the present TRIP steels. Those results are shown in the results and discussion of the present paper as fundamental data of each TRIP steel. Based on those results we conducted in situ neutron diffraction experiments in order to discuss the difference in uniform elongation between the needle-like $\gamma_{R}$ steel and the blocky $\gamma_{R}$ one.

Neutron diffraction experiments were conducted at TAKUMI, a high-resolution high-intensity time-of-flight (TOF) neutron diffractometer for engineering sciences at Materials and Life Science Experimental Facility (MLF) of Japan Proton Accelerator Research Complex (J-PARC). ${ }^{11,15)}$ The loading machine was installed at 45 degrees with respect to the incident neutron beam and the neutron diffraction profiles in the axial and transverse directions were recorded by two detector banks simultaneously. In the in situ neutron diffraction experiments during tensile deformation, tensile test specimens with a gage width of $6 \mathrm{~mm}$, gage length of $55 \mathrm{~mm}$ and thickness of $1.4 \mathrm{~mm}$ were prepared, and the strain rate was $6.1 \times 10^{-6} \mathrm{~s}^{-1}$ during elastic deformation and $1.8 \times 10^{-5} \mathrm{~s}^{-1}$ during plastic deformation.

The present paper analyzes the data from neutron diffraction patterns in the axial direction because it was difficult to separate the peaks between $\alpha$ and $\alpha^{\prime}$ in the patterns in the transverse direction ${ }^{11)}$ due to the proximity of the peaks caused by Poisson's effect.

The peak analyses of $\alpha$ were performed based on the previous papers by Harjo et al. ${ }^{11)}$ and Morooka et al. ${ }^{15)}$ Data analyses of $\alpha$ ' were conducted by a multi-peak fitting method because the peak positions of $\alpha$ and $\alpha$ were very close. The multi-peak fitting method is suitable for estimating lattice strains in crystals in which their diffraction peaks overlap and is considered to be applicable to materials with similar crystal structures. In the present analyses, $\alpha^{\prime}$ was considered as bcc with a higher carbon content than other bcc. This was because the reliability of separating the $a$ and $c$ axes is low because of the small volume fraction of $\alpha$ and because the carbon content dependence of $\alpha^{\prime}$ on the $c / a$ ratio is not clear. These assumptions were the same as those in Harjo et al.'s paper. ${ }^{11)}$ On the other hand, the annealed martensite of the matrix microstructure in the needle-like $\gamma_{R}$ steel was considered as bcc as will be mentioned later. Figure 1 shows the diffraction patterns for the needle-like $\gamma_{R}$ steel at true stress of $0 \mathrm{MPa}$ and $1105 \mathrm{MPa}$. Lattice strain $\left(\varepsilon_{h k l}\right)$ was calculated

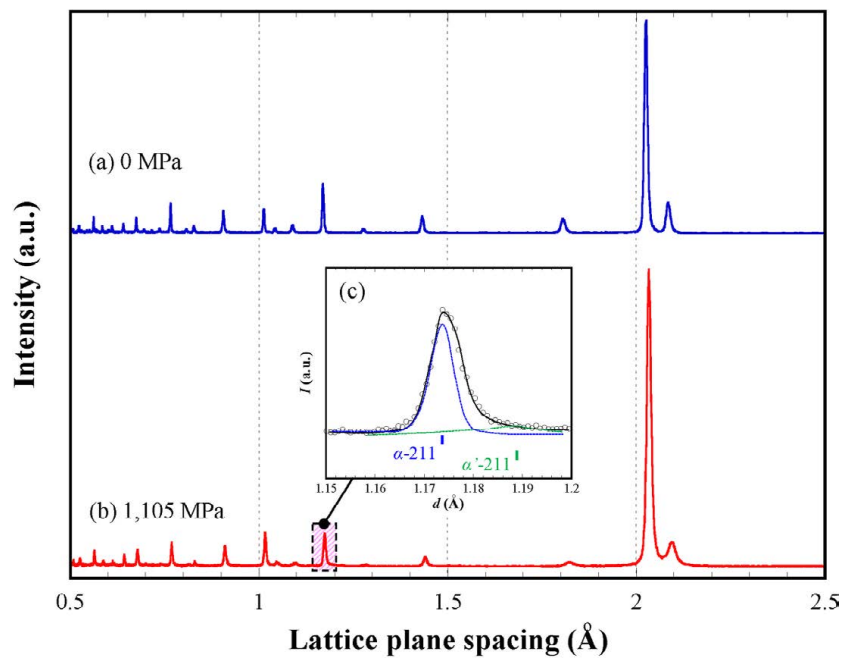

Fig. 1. Examples of diffraction pattern for the needle-like steel at true stress of $0 \mathrm{MPa}(\mathrm{a}), 1105 \mathrm{MPa}$ (b) and a typical fitting appearance using double peak contribution on diffraction peaks of $\alpha-211$ and $\alpha^{\prime}-211$ in the axial direction. (Online version in color.)

by using the following equation based on the peak analyses:

$$
\varepsilon_{h k l}=\frac{d_{h k l}-d_{h k l}^{0}}{d_{h k l}^{0}}
$$

where, $d_{h k l}$ is the lattice spacing during tensile deformation and $d_{h k l}^{0}$ the lattice spacing before deformation. $d_{h k l}^{0}$ of $\gamma$ and $\alpha$ were obtained by peak analyses before deformation. It is difficult to use $\alpha$ to analyze $d_{h k l}^{0}$ by peak analysis because $\alpha$ ' usually does not exist before deformation. In this study, $d_{h k l}^{0}$ of $\alpha^{\prime}$ was estimated from the calculated lattice constant of $\alpha^{\prime}$ as follows: $:^{19,20)}$

$$
a_{\alpha^{\prime}}=\sqrt[3]{\frac{\rho_{\gamma}}{2 \rho_{\alpha^{\prime}}}} a_{\gamma}
$$

where $a_{\alpha^{\prime}}, a_{\gamma}, \rho_{\alpha^{\prime}}$, and $\rho_{\gamma}$ are lattice constants and the atomic densities of $\alpha^{\prime}$ and $\gamma$, and $\rho_{\alpha}$, and $\rho_{\gamma}$ were calculated by using the following empirical equations: ${ }^{20}$ )

$$
\begin{aligned}
\rho_{\gamma}= & 8099.79-0.506 T-\left(118.26-7.39 \times 10^{-3} T\right) \\
X_{C}^{\gamma}- & 68.24 X_{S i}^{\gamma}-6.01 X_{M n}^{\gamma} \\
& \rho_{\alpha^{\prime}}=7875.96-0.297 T-5.62 \times 10^{-5} T^{2}- \\
& \left(206.35-7.78 \times 10^{-3} T-1.472 \times 10^{-6} T^{2}\right) \\
& X_{C}^{\alpha^{\prime}}-36.86 X_{S i}^{\alpha^{\prime}}-7.24 X_{M n}^{\alpha^{\prime}}
\end{aligned}
$$

where $T$ is temperature $\left({ }^{\circ} \mathrm{C}\right), X_{C}^{\gamma}, X_{C}^{\alpha^{\prime}}$ are carbon contents of $\gamma$ and $\alpha^{\prime}$ (in mass\%), and $X_{S i}^{\gamma}, X_{S i}^{\alpha^{\prime}}, X_{M n}^{\gamma}, X_{M n}^{\alpha^{\prime}}$ are the Si and Mn contents of $\gamma$ and $\alpha^{\prime}$. In the calculations, $T$ was assumed to be $23^{\circ} \mathrm{C}$ because of the deformation-induced martensitic transformation at room temperature, and it was also assumed that $X_{C}^{\gamma}=X_{C}^{\alpha^{\prime}}, X_{S i}^{\gamma}=X_{S i}^{\alpha^{\prime}}$, and $X_{M n}^{\gamma}=X_{M n}^{\alpha^{\prime}}{ }^{11)}$ The value of $X_{C}^{\gamma}$ was obtained by neutron diffraction experiments and the values of $X_{S i}^{\gamma}$ and $X_{M n}^{\gamma}$ were analyzed by electron probe microanalyzer (EPMA). The $a_{\alpha}$, before deformation $\left(a_{\alpha^{\prime}, 0}\right)$ of the two TRIP steels calculated by using Eqs. (3) and (4) were described by the $a_{\gamma}$ before deformation $\left(a_{\gamma, 0}\right)$ :

$$
\text { Needle-like } \gamma_{R} \text { steel : } \quad \alpha_{\alpha^{\prime}, 0}=0.8037 a_{\gamma, 0}
$$


Blocky $\gamma_{R}$ steel : $\quad \alpha_{\alpha^{\prime}, 0}=0.8030 a_{\gamma, 0}$

$d_{h k l}^{0}$ for $\alpha^{\prime}$ were calculated by using $a_{\alpha^{\prime}, 0}$ estimated by Eqs. (5) and (6) and were used for estimating the lattice strains of $\alpha^{\prime}$ using Eq. (1). ${ }^{11)}$

On the other hand, the volume fractions of $\gamma, \alpha$, and $\alpha$ were calculated by integrated intensities obtained by neutron diffraction experiments. ${ }^{11)}$ In terms of the change of volume fraction of $\alpha$ which is associated with the deformationinduced transformation behavior, the analyses of $\alpha$ ' peaks were evaluated as lower reliability because those peaks were low and broadened. Therefore, the increase of volume fraction of $\alpha^{\prime}$ was considered as the decrease of volume fraction of $\gamma$ from the analyses of $\gamma$ and $\alpha$ in this study. The volume fractions were calculated by the average values of integrated intensities ((111), (200), (311) for $\gamma$ phase and (110), (200), (211) for $\alpha$ phase, respectively) using the diffraction profiles in the axial and transverse directions. ${ }^{11)}$

\section{Experimental Results}

\subsection{Microstructures and Static Tensile Properties of 1 GPa-grade TRIP Steels}

Figure 2 shows optical micrographs of the needle-like $\gamma_{R}$ (a) and blocky $\gamma_{R}$ (b) steels. White indicates $\gamma_{R}$, blue indicates ferrite, and dark brown in Fig. 2(a) and brown in Fig. 2(b) indicate either bainite or martensite. ${ }^{10)}$ The volume fraction of $\gamma_{R}$ estimated by neutron diffraction experiments is $20 \%$ for the needle-like $\gamma_{R}$ steel and $18 \%$ for the blocky $\gamma_{R}$ one. The matrix microstructure of the needle-like $\gamma_{R}$ steel is martensite annealed at $1033-1053 \mathrm{~K}$ (annealed martensite) and that of the blocky $\gamma_{R}$ one is polygonal ferrite which is obtained by recovery or recrystallization at 1033 to $1053 \mathrm{~K}$ after cold rolling. Both of the TRIP steels also contained a small amount of bainitic ferrite obtained at $673 \mathrm{~K}$. The carbon in bainitic ferrite is eliminated to $\gamma$ and its carbon content is almost the same as those of annealed martensite and polygonal ferrite. Because it is therefore difficult to separate the peaks among the bainitic ferrite, annealed martensite and polygonal ferrite, those three microstructures were considered as bcc with low carbon contents in the present paper.

Figure 3 shows nominal stress-strain curves obtained by static tensile tests at a strain rate of $3.3 \times 10^{-5} \mathrm{~s}^{-1}$ at $296 \mathrm{~K}^{10)}$ The $0.2 \%$ proof strength, tensile strength, uni- form elongation and total elongation of the needle-like $\gamma_{R}$ steel were $693 \mathrm{MPa}, 995 \mathrm{MPa}, 34 \%$, and $39 \%$, and those of the blocky $\gamma_{R}$ one were $550 \mathrm{MPa}, 1,009 \mathrm{MPa}, 27 \%$, and $29 \%$, respectively. The tensile strength was approximately $1 \mathrm{GPa}$ and was independent of the $\gamma_{R}$ morphology but the $0.2 \%$ proof strength, uniform elongation, and total elongation were larger in the needle-like $\gamma_{R}$ steel. Especially, we noted that the needle-like $\gamma_{R}$ steel indicated about 7\% larger uniform elongation despite its $1 \mathrm{GPa}$-grade tensile strength. Figure 4 shows the relationship between true stress and work-hardening rate in order to discuss the difference of uniform elongation between the needle-like $\gamma_{R}$ steel and the blocky $\gamma_{R}$ one. The point at which the true stress becomes identical to the work-hardening rate indicates the tensile strength and uniform elongation in the nominal stress-strain curve. ${ }^{21)}$ In Fig. 4(a), the work-hardening rate was larger in the blocky $\gamma_{R}$ steel at low true strain but that of the needlelike $\gamma_{R}$ steel became larger when true strain exceeded about 0.15 . In particular, the work-hardening rate of the needlelike $\gamma_{R}$ steel remained almost the same when true strain was between 0.1 and 0.2. As can be seen in Fig. 4(b), the work-hardening rate of the needle-like $\gamma_{R}$ steel was almost constant at true stresses between about 900 and $1150 \mathrm{MPa}$

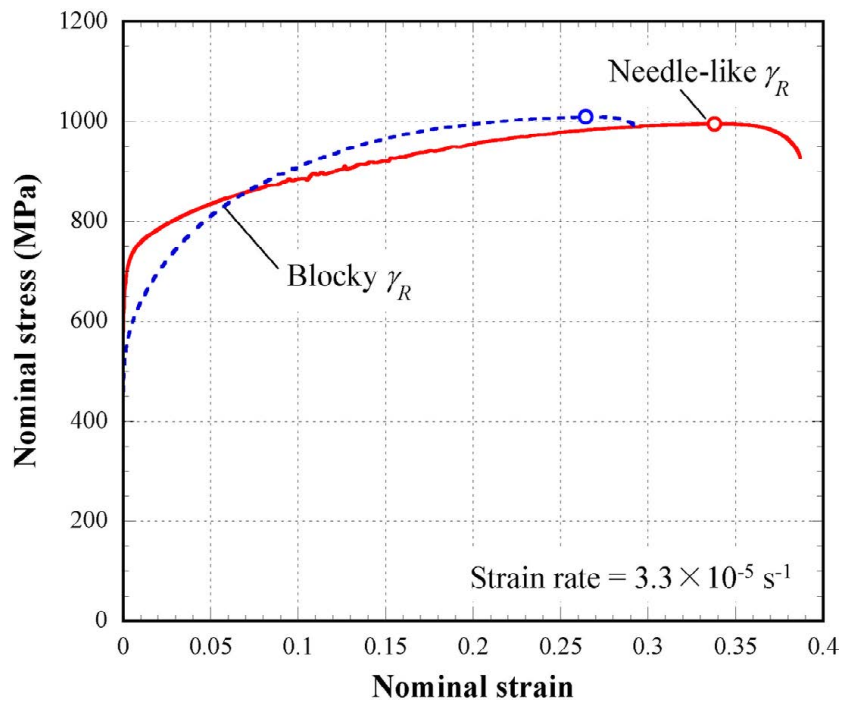

Fig. 3. Nominal stress-strain curves of the 1 GPa-grade TRIP steels with different $\gamma_{R}$ shapes obtained by static tensile tests at $296 \mathrm{~K}$. (Online version in color.)

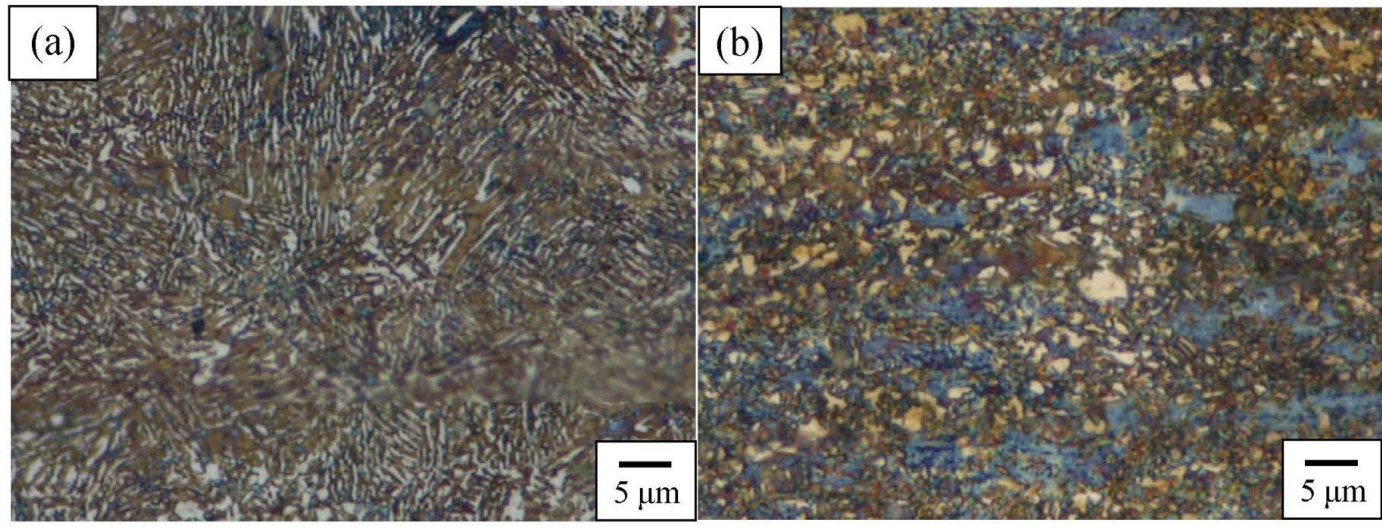

Fig. 2. Optical micrographs of the 1 GPa-grade TRIP steels with different $\gamma_{R}$ shapes of needle-like (a) and blocky (b) (Online version in color.) 


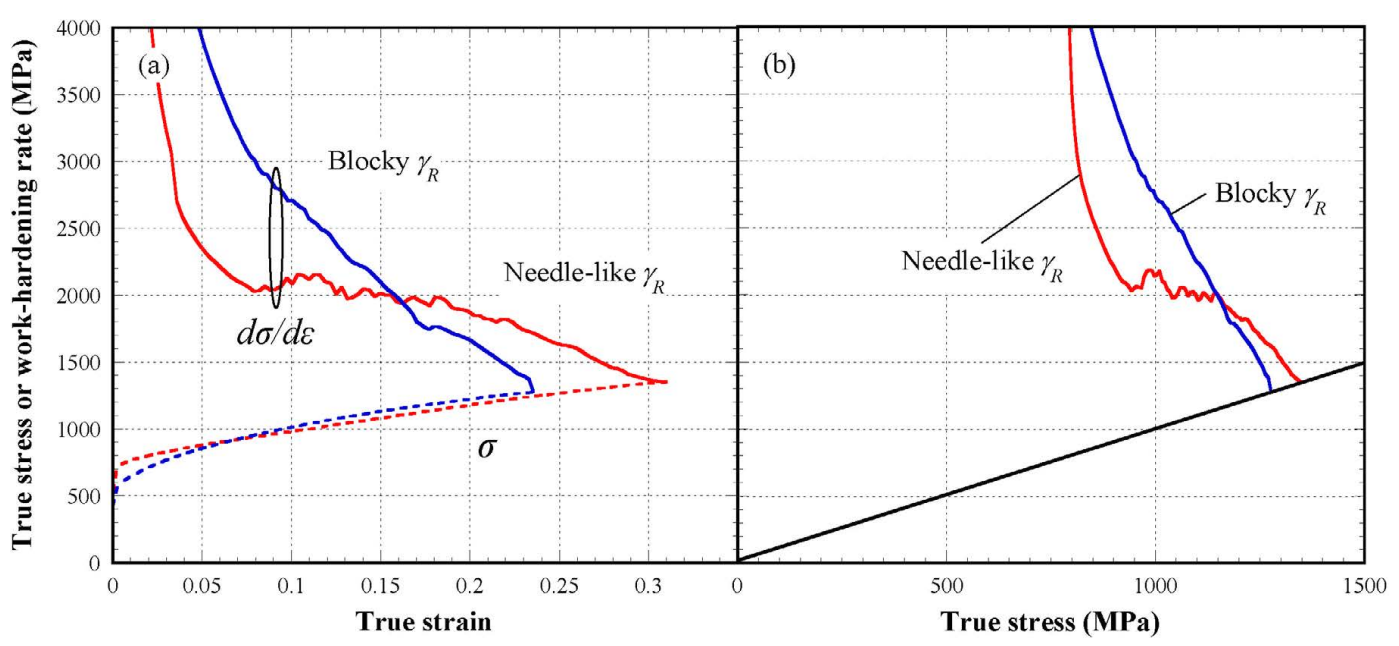

Fig. 4. (a) True stress and work-hardening rate as functions of true strain and (b) work-hardening rate as a function of true stress in the $1 \mathrm{GPa}$-grade TRIP steels with different $\gamma_{R}$ shapes at the strain rates of $3.3 \times 10^{-5} \mathrm{~s}^{-1}$ at $296 \mathrm{~K}$. (Online version in color.)

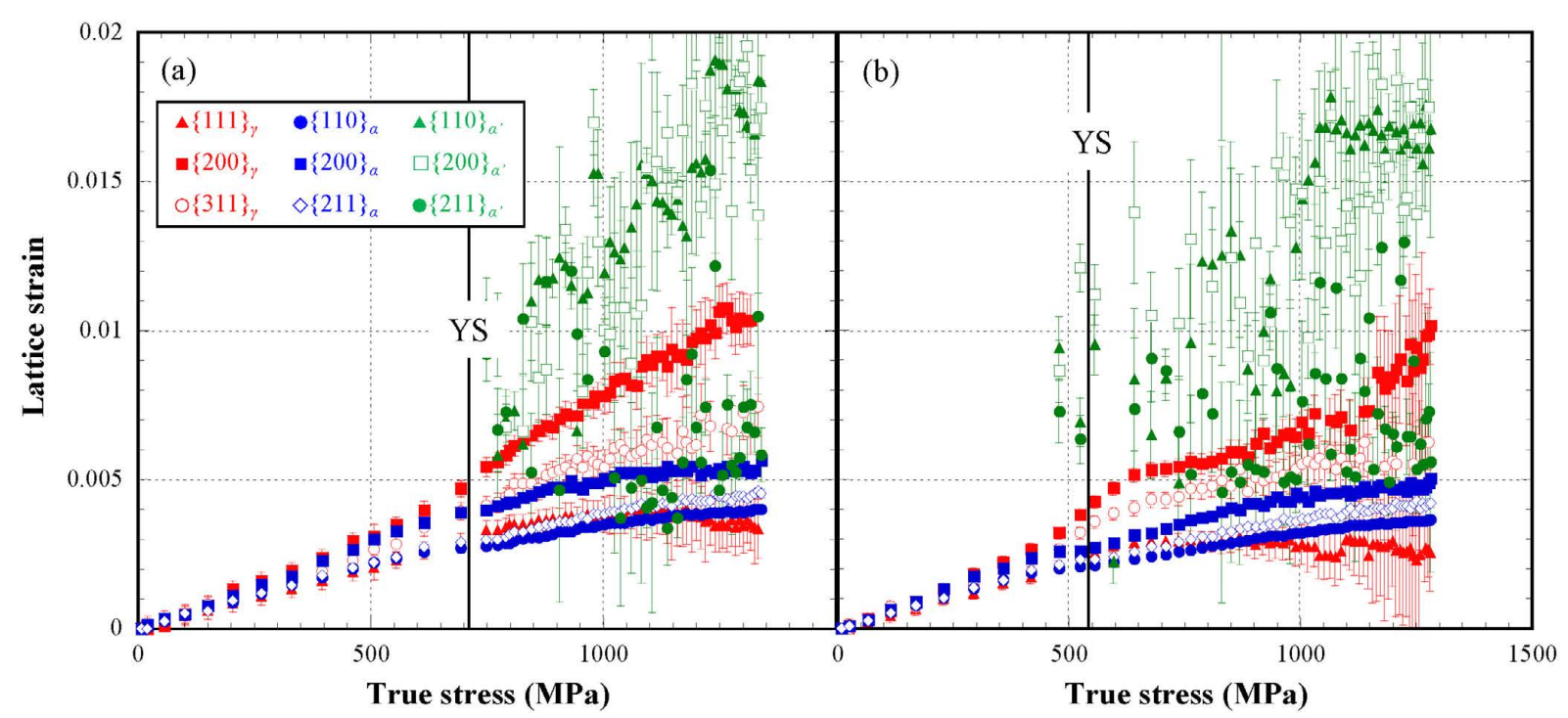

Fig. 5. Lattice strains for austenite $(\gamma)$, ferrite $(\alpha)$ and martensite $\left(\alpha^{\prime}\right)$ phases in the axial direction during tensile deformation of the 1 GPa-grade TRIP steels with $\gamma_{R}$ shapes of needle-like (a) and blocky (b). (Online version in color.)

and became larger than the blocky $\gamma_{R}$ one at true stresses of more than $1150 \mathrm{MPa}$. Therefore, the better uniform elongation of the needle-like $\gamma_{R}$ steel can be ascribed to the larger work-hardening rate at larger strain or stress range from the viewpoint of the stress-strain relationship.

\subsection{Results of in situ Neutron Diffraction Experiments during Tensile Deformation}

Figure 5 shows lattice strains of $\alpha, \gamma$, and $\alpha^{\prime}$ as functions of true stress obtained by the in situ neutron diffraction experiments. Three lattice strains were shown for each phase and YS means the $0.2 \%$ proof strength in the tensile test. The lattice strains were dependent on phase and grains. The Young's modulus in the elastic region and the magnitude relationship among the lattice strains of each phase tended to make little difference from the results of neutron diffraction experiments using various TRIP steels reported so far. ${ }^{11-14)}$ Both the lattice strains of $\alpha$ and $\gamma$ deviated from the linear relationship before YS in the needle-like and the blocky $\gamma_{R}$ steels, and the lattice strain of $\alpha$ stopped increasing. This suggests that $\alpha$ yielded and plastic defor- mation started. When the changes in the lattice strain of $\gamma$ were compared, the changes in the lattice strains of $\{200\}_{\gamma}$ and $\{311\}_{\gamma}$ grains differed between the needle-like and the blocky $\gamma_{R}$ steels; the increase of their lattice strains with true stress was larger in the needle-like $\gamma_{R}$ steel. Also, looking at the difference in lattice strain, which is related to the work hardening of each phase and the stress partitioning, there was no significant difference for $\alpha^{\prime}$ between the needle-like $\gamma_{R}$ steel and the blocky one. However, the difference of lattice strains between $\alpha$ and $\gamma$ was larger in the needle-like $\gamma_{R}$ steel.

Figure 6 shows the phase strains of $\alpha, \gamma$, and $\alpha^{\prime}$ as functions of true stress in the needle-like $\gamma_{R}$ and blocky $\gamma_{R}$ steels. Here, phase strain means the averaged lattice strain of each phase seen in Fig. 5. The phase strain of $\alpha$ ' was the largest among the three phases and their changes were almost independent of $\gamma_{R}$ morphology. Figure 7 shows the phase strains of only $\alpha$ and $\gamma$ without $\alpha^{\prime}$ as functions of true stress in order to compare their changes between the needle-like $\gamma_{R}$ steel and the blocky $\gamma_{R}$ one to make it clear the difference of phase strains between $\alpha$ and $\gamma$. The difference of phase 


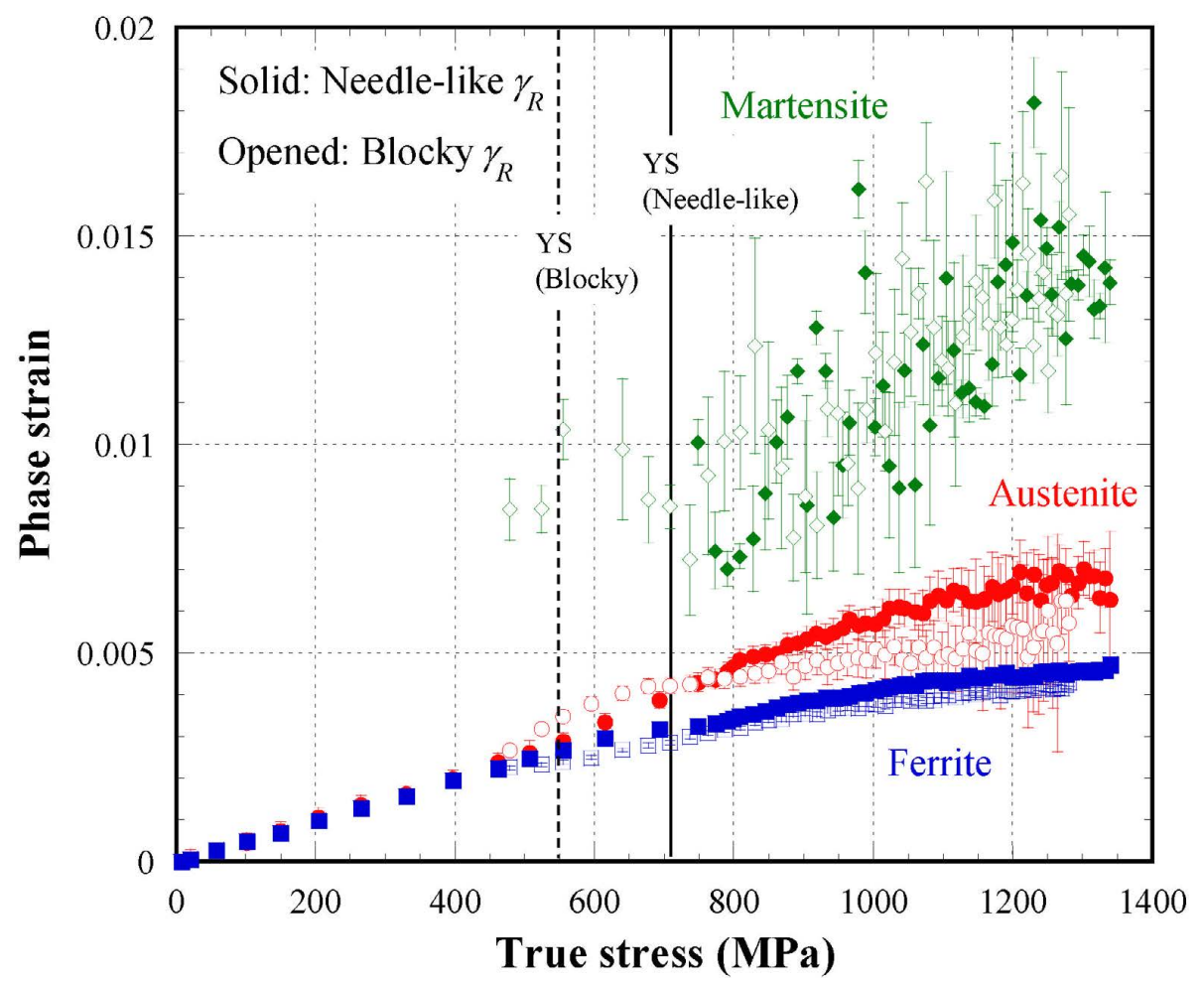

Fig. 6. Phase strains for austenite, ferrite and martensite phases in the axial direction during tensile deformation of the 1 GPa-grade TRIP steels with $\gamma_{R}$ shapes. Here, YS means the yield strength obtained by the static tensile tests. (Online version in color.)

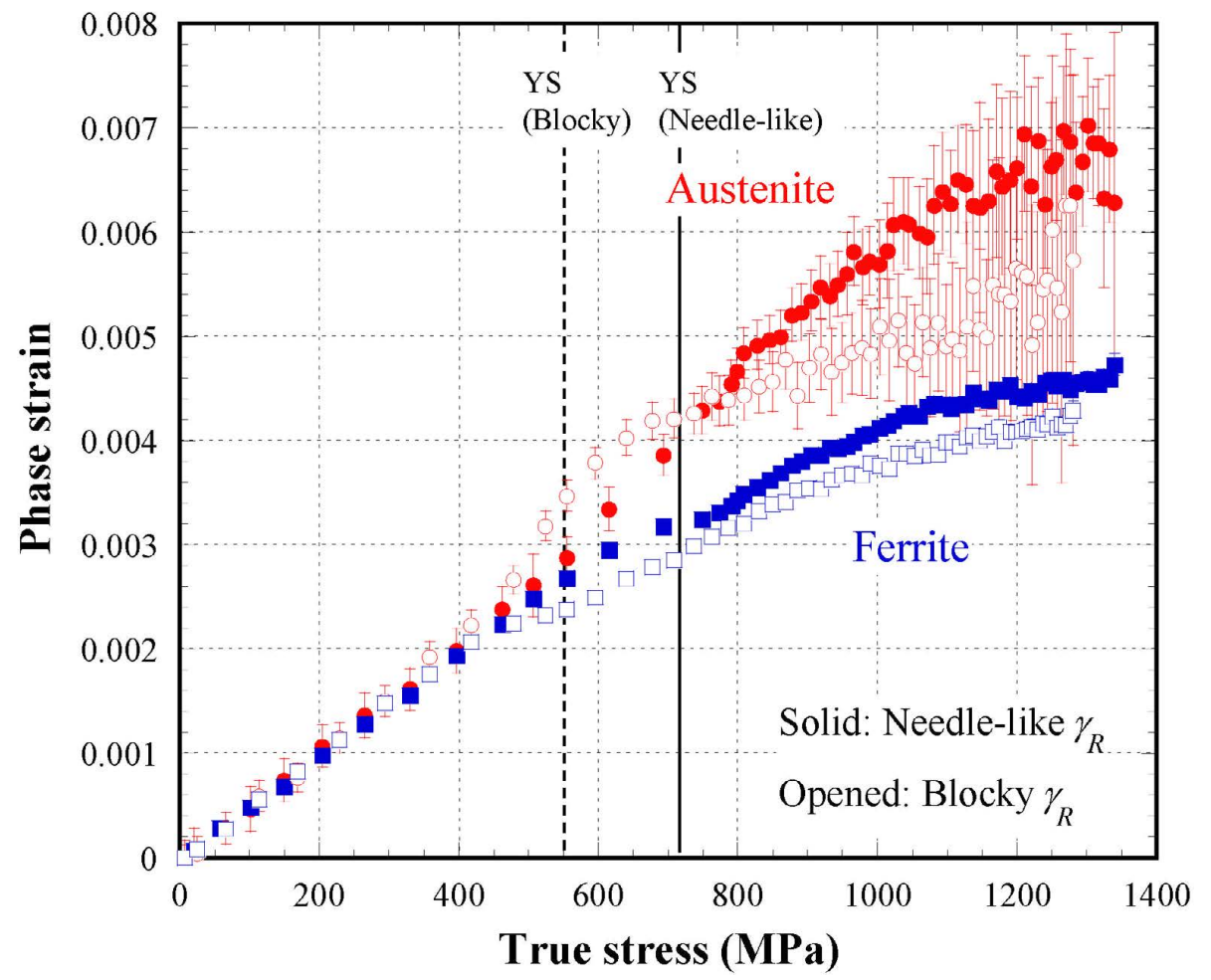

Fig. 7. Phase strains for austenite and ferrite phases in the axial direction evaluated during tensile deformation of the 1 GPa-grade TRIP steels with $\gamma_{R}$ shapes. Here, YS means the yield strength obtained by the static tensile tests. (Online version in color.)

strains between $\alpha$ and $\gamma$ with true stress is shown in Fig. 8 . Stress partitioning was confirmed before YS in both steels even though the YS were different from each other. The difference of phase strains between $\alpha$ and $\gamma$ was larger in the blocky $\gamma_{R}$ steel from YS to about $800 \mathrm{MPa}$ but that of the needle-like $\gamma_{R}$ steel became larger over $800 \mathrm{MPa}$. The phase strain of $\gamma$ in the needle-like $\gamma_{R}$ steel became larger than that in the blocky $\gamma_{R}$ one at true stresses of more than $800 \mathrm{MPa}$ and the increase of phase strain of $\gamma$ was also larger in the needle-like $\gamma_{R}$ steel. The difference of phase 
strains is associated with work hardening behavior and the larger the difference of phase strains the larger the work hardening becomes. ${ }^{15-17)}$ As seen, the difference of phase strains between $\alpha$ and $\gamma$ from yielding to true stress of about $800 \mathrm{MPa}$ was larger in the blocky $\gamma_{R}$ steel but that at true stress of $800 \mathrm{MPa}$ and over was larger in the needle-like $\gamma_{R}$ steel. Such difference of phase strains between $\alpha$ and $\gamma$ seems to be associated with the behavior of work-hardening rate as seen in Fig. 4.

Figure 9 shows changes of the volume fractions of $\gamma_{R}$ and $\alpha^{\prime}$ with true strain (a) and true stress (b). ${ }^{10,22)}$ The arrows in Fig. 9(b) indicate the yield strength of each TRIP steel. In Fig. 9(a), the volume fraction of $\alpha^{\prime}$ at a given true strain was larger in the blocky $\gamma_{R}$ steel but that at the maximum load point was almost the same at about 10\%. In Fig. 9(b), the blocky $\gamma_{R}$ steel started the deformation-induced martensitic transformation before yielding whereas the needlelike $\gamma_{R}$ steel started the transformation after yielding. The mechanical stability of $\gamma_{R}$ was thus found to be higher in the needle-like $\gamma_{R}$ steel. The volume fractions of $\gamma_{R}$ and $\alpha^{\prime}$

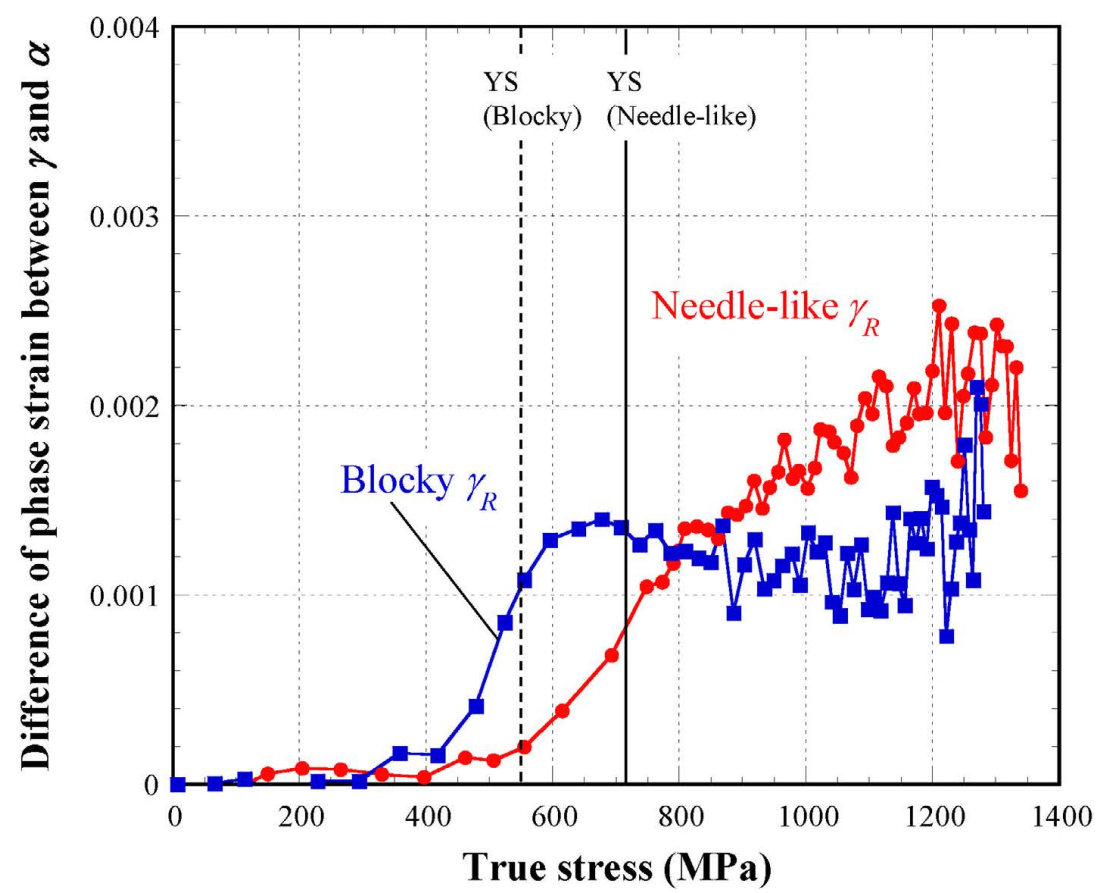

Fig. 8. Difference of phase strain between austenite $(\gamma)$ and ferrite $(\alpha)$ phases during tensile deformation of the $1 \mathrm{GPa}-$ grade TRIP steels with $\gamma_{R}$ shapes. Here, YS means the yield strength obtained by the static tensile tests. (Online version in color.)

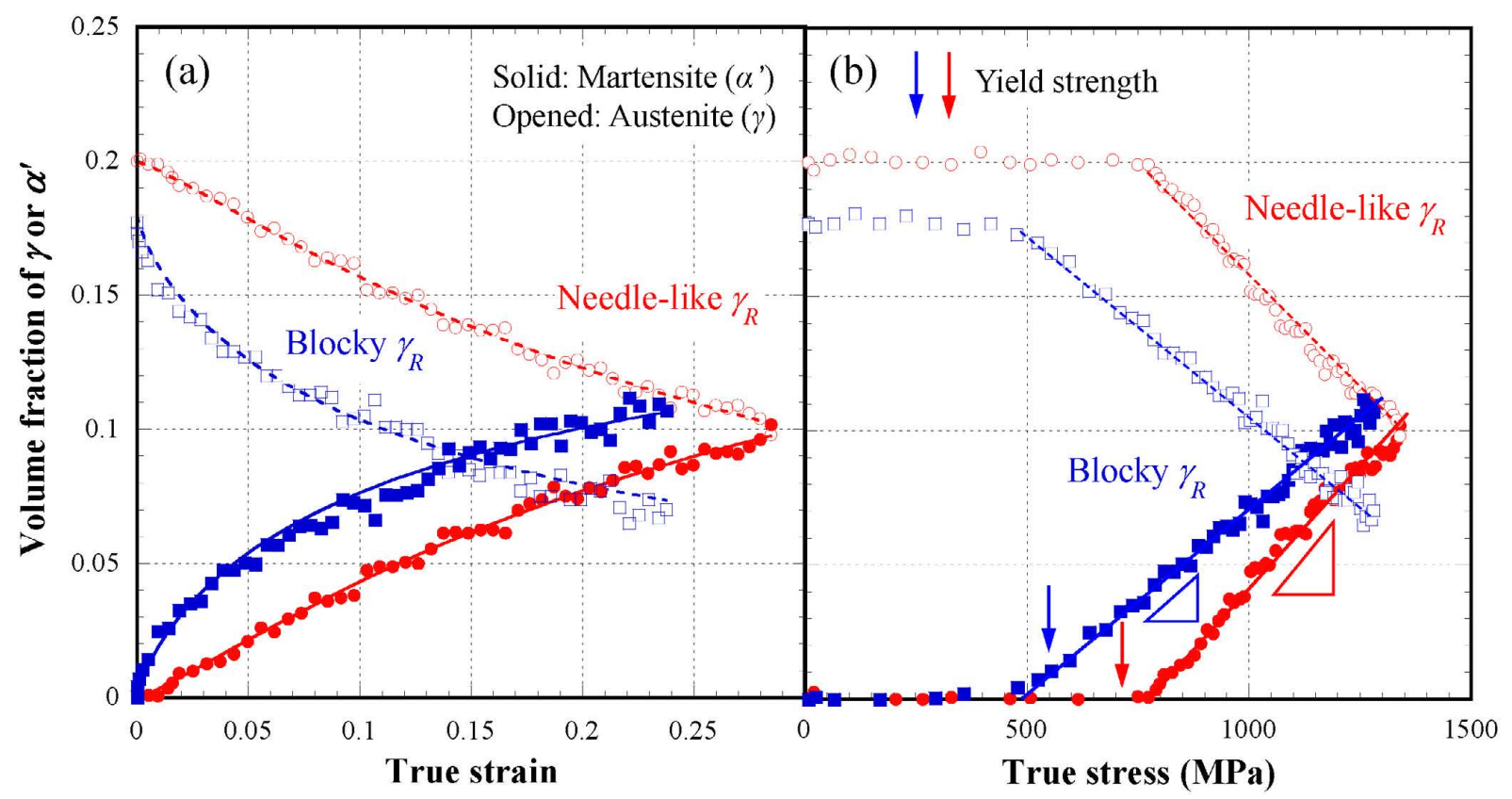

Fig. 9. Volume fractions of retained austenite $(\gamma)$ and deformation-induced martensite $\left(\alpha^{\prime}\right)$ as functions of true strain (a) and true stress (b) in the 1 GPa-grade TRIP steels with $\gamma_{R}$ shapes. Here, arrows in Fig. 9(b) show the yield strength obtained by the static tensile tests. (Online version in color.) 
changed linearly with increasing true stress and the slope for $\alpha^{\prime}$ was larger in the needle-like $\gamma_{R}$ steel. Therefore, the transformation amount of $\alpha$ ' against true stress was higher in the needle-like $\gamma_{R}$ steel. The transformation amount of $\alpha$ against true stress in the needle-like and blocky $\gamma_{R}$ steels were $0.0179 \% / \mathrm{MPa}$ and $0.0125 \% / \mathrm{MPa}$, respectively. In TRIP steels, the transformation behavior whereby $\gamma_{R}$ transforms to $\alpha^{\prime}$ actively at the latter part of deformation effectively improves the elongation and ductility due to the TRIP effect. ${ }^{1,4,23,24)}$ Therefore, the volume fraction of $\gamma_{R}$ and the transformation amount of $\alpha^{\prime}$ at larger stress range are major reasons for the better uniform elongation of the needle-like $\gamma_{R}$ steel.

In the TRIP steels studied by Harjo et al., ${ }^{11)}$ the changes of phase and lattice strains and the deformation-induced transformation behavior during tensile deformation corresponded approximately to those of the blocky $\gamma_{R}$ steel in this study. The $\gamma_{R}$ morphology was blocky shape and the matrix microstructure was ferrite-bainite ${ }^{10,11)}$ in both the blocky $\gamma_{R}$ steel and the TRIP steels studied by Harjo et $a l$. Therefore, the deformation behavior of $\alpha$ and $\gamma$ phases seems to be associated with the $\gamma_{R}$ morphology and the matrix microstructure.

\section{Discussions of the Better Uniform Elongation of the Needle-like $\gamma_{R}$ Steel}

The reasons for $1 \mathrm{GPa}$-grade high strength and better uniform elongation in the needle-like $\gamma_{R}$ steel will be discussed here with reference to Figs. 5 to 9. As seen in Figs. 3 and 4 , the larger work-hardening rate at larger strain or larger stress range can be ascribed to the better uniform elongation of the needle-like $\gamma_{R}$ steel from the macroscopic stress-strain relationship. The stress-strain relationship of the needle-like $\gamma_{R}$ steel is discussed based on the deformation-induced martensitic transformation behavior of $\gamma_{R}$, the phase strains and the work hardening behavior from the differences between $\gamma$ and $\alpha$ phases.

\subsection{Deformation-induced Martensitic Transformation Behavior}

From the previous studies of metastable austenitic steels $^{1,2)}$ in the $1960 \mathrm{~s}$ to $1970 \mathrm{~s}$, the deformation-induced transformation whereby $\gamma_{R}$ is mechanically stable in the early stage of deformation and transforms to $\alpha^{\prime}$ actively at the latter part of deformation effectively contributes to the TRIP effect. For example, Tsuchida et al. ${ }^{23,24)}$ reported the quantitative conditions of deformation-induced transformation to obtain better uniform elongation due to the TRIP effect in metastable austenitic stainless steels. On the other hand, as seen in Fig. 9(b), the volume fraction of $\alpha^{\prime}$ linearly increased as a function of true stress and the increase of the volume fraction of $\alpha^{\prime}$ against true stress was larger in the needle-like $\gamma_{R}$ steel. Furthermore, the needle-like $\gamma_{R}$ steel started the deformation-induced transformation of $\gamma_{R}$ after yielding. Therefore, the volume fraction of $\gamma_{R}$ and the increase of $\alpha^{\prime}$ at larger stress or larger strain range were larger in the needle-like $\gamma_{R}$ steel. This deformation-induced transformation behavior also coincides with the qualitative conditions of deformation-induced transformation to obtain a better TRIP effect previously reported elsewhere. ${ }^{1,23,24)}$
Considering the better uniform elongation of the needle-like $\gamma_{R}$ steel from the viewpoint of deformation-induced transformation, the two conditions that the mechanical stability of $\gamma_{R}$ is high and that the increase of $\alpha^{\prime}$ at the larger stress or strain range is large seem to be the same as conventional findings. On the other hand, because the volume fraction of $\alpha^{\prime}$ at the maximum load point was almost the same in the needle-like and blocky $\gamma_{R}$ steels, it is difficult to explain the difference of uniform elongation between the present two TRIP steels from only the deformation-induced transformation behavior.

\subsection{Phase Strain of $\gamma$ Phase and Difference of Phase Strains between $\gamma$ and $\alpha$}

The constituent phases of TRIP steels are $\alpha, \gamma$, and $\alpha^{\prime}$, and the volume fraction of $\alpha^{\prime}$ at the maximum load point was approximately $10 \%$ independent of the $\gamma_{R}$ morphology. Therefore, the deformation behavior of $\gamma$ and $\alpha$ whose volume fraction is about $90 \%$ should be considered. The phase strain of $\alpha^{\prime}$ as seen in Fig. 6 and the estimated stress of $\alpha^{11)}$ were almost the same between the needle-like and blocky $\gamma_{R}$ steels. The effect of $\alpha^{\prime}$ on flow stress in TRIP steels is also related to the volume fraction. The fact that the tensile strength of the present two TRIP steels was almost the same seems to be closely associated with the volume fraction of $\alpha^{\prime}$ at the maximum load point. Therefore, it is concluded that the phase strain of $\alpha^{\prime}$ does not greatly influence the better uniform elongation of the needle-like $\gamma_{R}$ steel.

In the changes of phase strain as seen in Figs. 6 and 8, the phase strain of $\gamma$ and the difference of phase strains between $\gamma$ and $\alpha$ were different in the present two types of TRIP steels. The phase strain of $\gamma$ in the needle-like $\gamma_{R}$ steel was smaller than that of the blocky $\gamma_{R}$ steel at YS. However, not only the phase strain of $\gamma$ but also its rate of increase became larger at true stresses of more than $800 \mathrm{MPa}$ in the needle-like $\gamma_{R}$ steel. The difference of phase strain between $\gamma$ and $\alpha$ in the two TRIP steels also changed in the same manner as the phase strain of $\gamma$.

The phase strain of $\gamma$ is usually larger than that of $\alpha$ in TRIP steels. ${ }^{11-13)}$ In the changes of phase strain during tensile deformation, the increase in the phase strain of $\alpha$ stagnated whereas the increase in the phase strain of $\gamma$ became larger. This means that stress partitioning between $\alpha$ and $\gamma$ occurred because the stress of $\gamma$ increased whereas that of $\alpha$ decreased due to the plastic deformation of $\alpha .^{11-13,17)}$ As can be seen in Figs. 7 and 8 , in the blocky $\gamma_{R}$ steel, the true stress at the onset of stress partitioning was smaller and the difference of phase strains between $\alpha$ and $\gamma$ at YS was larger. On the other hand, in the blocky $\gamma_{R}$ steel, the increase in the phase strain of $\gamma$ stagnated at the true stress of more than $600 \mathrm{MPa}$. This means that $\gamma$ started plastic deformation. In the case of the needle-like $\gamma_{R}$ steel, the difference of phase strain at YS was smaller than that of the blocky $\gamma_{R}$ one and the phase strain of $\gamma$ continued increasing until true stress of about $1200 \mathrm{MPa}$. That is, the changes of phase strain of $\gamma$ were different between the needle-like $\gamma_{R}$ steel and the blocky $\gamma_{R}$ one and such behavior is associated with the changes of the difference of phase strains between $\gamma$ and $\alpha$. The larger the difference of phase strain, the larger the work hardening becomes. However, the work hardening does not have to be large immediately after yielding in order 
to improve uniform elongation. ${ }^{21,23-25)}$ In the blocky $\gamma_{R}$ steel, $\gamma$ easily transformed to $\alpha$ ' because the phase strain and the stress of $\gamma$ were larger after YS. ${ }^{26)}$ On the other hand, in the needle-like $\gamma_{R}$ steel, the deformation-induced transformation was active at true stress of $800 \mathrm{MPa}$ and over because both the phase strain of $\gamma$ and the difference of phase strains were larger at the same true stress range. This effectively contributes to the TRIP effect and the transformation amount of $\alpha$ against true stress was larger in the needle-like $\gamma_{R}$ steel, as seen in Fig. 9. That is, the larger difference of phase strains and the larger phase strain of $\gamma$ at the latter part of deformation effectively contribute to the TRIP effect because of not only the larger heterogeneity between phases but also the larger deformation-induced transformation of $\gamma_{R}$. For the mechanical stability of $\gamma_{R}$, it is desirable that the stress of $\gamma_{R}$ and the difference of phase strains are smaller at the early stage of deformation. The phase strain of $\alpha$ as a matrix microstructure is important when considering the difference of phase strains between $\gamma$ and $\alpha$. The matrix microstructure of annealed martensite in the needle-like $\gamma_{R}$ steel is an important factor because of the larger phase strain of $\alpha$.

Figure 10 summarizes schematically the reasons for the better uniform elongation of the needle-like $\gamma_{R}$ steel. At first, its better uniform elongation is ascribed to the larger workhardening rate, especially the constant values at true stresses between 900 and $1200 \mathrm{MPa}$, from the stress-strain relationship. The tensile deformation behavior in which the workhardening rate was almost constant is discussed in terms of the deformation-induced transformation behavior, the phase strain of $\gamma$, and the difference of phase strains between $\gamma$ and $\alpha$ obtained by the neutron diffraction experiments. The difference of phase strains between $\gamma$ and $\alpha$ became larger in the needle-like $\gamma_{R}$ steel from true stress of $800 \mathrm{MPa}$ because the phase strain of $\gamma$ continued increasing. The deformationinduced transformation started at true stress of $800 \mathrm{MPa}$ and the transformation amount of $\alpha^{\prime}$ against true stress was also larger in the needle-like $\gamma_{R}$ steel. This larger difference of phase strains and the deformation-induced transformation behavior of the needle-like $\gamma_{R}$ steel led to an almost constant work-hardening rate. The work-hardening rate of the

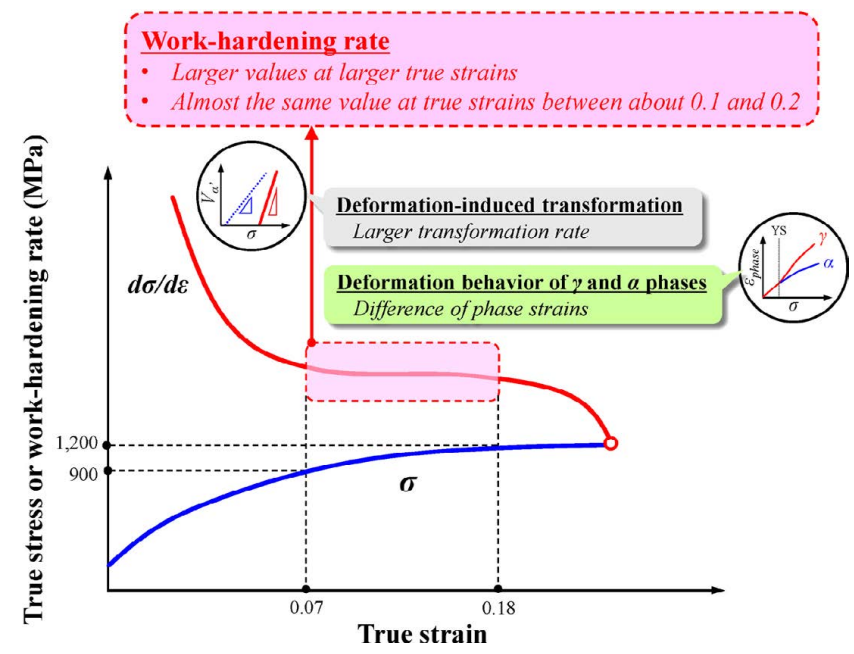

Fig. 10. Schematic illustration of the discussions for the better uniform elongation in the needle-like $\gamma_{R}$ steel from in situ neutron diffraction experiments. (Online version in color.) needle-like $\gamma_{R}$ steel remained almost constant as long as $\gamma_{R}$ continued to transform to $\alpha^{\prime}$ at a certain rate and the difference of phase strains also continued increasing but started to decrease at about $1200 \mathrm{MPa}$ at which the increase in the difference of phase strains became smaller. The abovementioned TRIP effect due to the deformation-induced transformation behavior and the deformation behavior of $\gamma$ and $\alpha$ contributed to the better uniform elongation of the $1 \mathrm{GPa}$-grade needle-like $\gamma_{R}$ steel.

From the above results and discussions, heterogeneity is an important factor when discussing the better uniform elongation of the needle-like $\gamma_{R}$ steel. This includes not only the increase of heterogeneity due to the deformation-induced transformation from $\gamma$ to $\alpha$ ' but also the heterogeneity between $\gamma$ and $\alpha$. Those are related since the heterogeneity is smaller at the early stage of deformation and becomes larger during tensile deformation. The TRIP effect is a strengthening mechanism of steel involving the increase of heterogeneity between $\gamma$ and $\alpha^{\prime}$ due to the deformation-induced transformation. ${ }^{1,4,24,27)}$ The present in situ neutron diffraction experiments revealed that the increase of heterogeneity between $\alpha$ and $\gamma$ is closely associated with the better TRIP effect. The heterogeneity among phases is related to not only the work hardening behavior ${ }^{15-17)}$ but also the deformationinduced transformation of $\gamma_{R}$. In the present TRIP steels, the larger the difference of phase strains between $\alpha$ and $\gamma$, the larger the increase of $\alpha^{\prime}$ becomes because of the larger stress of $\gamma_{R}$.

The following two conditions were found from the present study. One is that the difference of phase strains between $\gamma$ and $\alpha$ becomes larger during tensile deformation and this leads to a larger work hardening in the latter part of deformation. The other is that the phase strain of $\gamma$ continues to increase up to larger stresses or larger strains. The larger phase strain of $\gamma$ means that $\gamma$ behaves as a harder phase and that the deformation-induced martensitic transformation of $\gamma_{R}$ is encouraged. It is concluded that these two conditions are important guidelines to obtain better elongation due to the TRIP effect in high-strength TRIP steels. Furthermore, the deformation behavior of $\gamma$ seems to be influenced by the deformation behavior of $\alpha$ with larger volume fractions. in situ neutron diffraction experiments which can discuss the macroscopic stress-strain relationship in terms of the deformation behavior of phases and grains can thus play an important role for understanding the TRIP effect. ${ }^{11-18)}$

\section{Summary}

In this study, in situ neutron diffraction experiments during tensile deformation were conducted using two types of high-strength TRIP steels with different $\gamma_{R}$ morphologies obtained from $0.3 \% \mathrm{C}$ steel. The deformation behavior of each grain and each phase and the deformation-induced martensitic transformation behavior of $\gamma_{R}$ were summarized, and reasons for the better uniform elongation of needle-like $\gamma_{R}$ steel were discussed. The following conclusions were drawn:

(1) Changes of lattice strains and phase strains of martensite phase $\left(\alpha^{\prime}\right)$ were almost independent of $\gamma_{R}$ morphology. The difference of phase strains between austenite phase $(\gamma)$ and ferrite phase $(\alpha)$ was larger in the needle-like $\gamma_{R}$ 
steel at larger true stress range because the phase strain of $\gamma$ increased up to true stress of about $1200 \mathrm{MPa}$.

(2) The volume fraction of deformation-induced martensite can be summarized as a function of true stress with a linear relationship in the present two TRIP steels. The mechanical stability of $\gamma_{R}$ was higher and the transformation amount of $\alpha^{\prime}$ against true stress was also larger in the needle-like $\gamma_{R}$ steel.

(3) It is concluded from in situ neutron diffraction experiments during tensile deformation that the better uniform elongation of the needle-like $\gamma_{R}$ steel is ascribed to the increase in the degree of heterogeneity of deformationinduced transformation and deformation behavior of $\gamma$ and $\alpha$ up to large stresses or strains. Especially, stress in $\gamma$ and its change during tensile deformation were found to be associated with not only the stress-strain relationship of TRIP steels but also the deformation-induced martensitic transformation behavior of $\gamma_{R}$.

(4) Important conditions for better uniform elongation due to the TRIP effect in high-strength TRIP steels are that the stress partitioning between $\gamma$ and $\alpha$ is small immediately after yielding and becomes larger with an increase in stress or strain, and that the phase strain of $\gamma$ continues to increase after yielding.

\section{Acknowledgments}

This study was obtained as a result of a commissioned project by a New Energy and Industrial Technology Development Organization (NEDO), and the support is greatly appreciated. The authors are also grateful to Dr. S. Harjo, Dr. T. Kawasaki of J-PARC center, Japan Atomic Energy Agency (JAEA) and Dr. G. Wu of Kyoto University.

\section{REFERENCES}

1) I. Tamura: Tetsu-to-Hagané, 56 (1970), 429 (in Japanese).

2) T. Angel: J. Iron Steel Inst., 177 (1954), 165.

3) K. Sugimoto, M. Kobayashi and S. Hashimoto: Metall. Trans. A, 23 (1992), 3085.

4) O. Matsumura, Y. Sakuma and H. Takechi: Trans. Iron Steel Inst. Jpn., 27 (1987), 570.

5) N. Tsuchida and K. Osaki: Tetsu-to-Hagané, 99 (2013), 524 (in Japanese).

6) N. Tsuchida, T. Araki, Y. Yamaguchi and K. Fukaura: Tetsu-toHagané, 98 (2012), 558 (in Japanese).

7) M. Mukherjee, O. N. Mohanty, S. Hashimoto, T. Hojo and K. Sugimoto: ISIJ Int., 46 (2006), 316.

8) K. Sugimoto, J. Kobayashi and T. Hojo: Tetsu-to-Hagané, 103 (2017), 1 (in Japanese).

9) M. Takahashi: Tetsu-to-Hagané, 100 (2014), 82 (in Japanese).

10) N. Tsuchida, S. Ohkura, T. Tanaka and Y. Toji: Tetsu-to-Hagané, 103 (2017), 597 (in Japanese).

11) S. Harjo, N. Tsuchida, J. Abe and W. Gong: Sci. Rep., 7 (2017), 15149. https://doi.org/10.1038/s41598-017-15252-5

12) A. Narui, S.-C. Chen, Y. Tomota and T. Kamiyama: Trans. Jpn. Soc. Mech. Eng. A, 75 (2009), 501 (in Japanese).

13) Y. Tomota, H. Tokuda, Y. Adachi, M. Wakita, N. Minakawa, A. Moriai and Y. Morii: Acta Mater., 52 (2004), 5737.

14) K. Asoo, Y. Tomota, S. Harjo and Y. Okitsu: ISIJ Int., 51 (2011), 145.

15) S. Morooka, O. Umezawa, S. Harjo, K. Hasegawa and Y. Toji: Tetsuto-Hagané, 98 (2012), 311 (in Japanese).

16) M. Ojima, Y. Adachi, Y. Tomota, K. Ikeda, T. Kamiyama and Y. Katada: Mater. Sci. Eng. A, 527 (2009), 16.

17) S. Harjo, Y. Tomota, P. Lukas, D. Neov, M. Vrana, P. Mikula and M. Ono: Acta Mater., 49 (2001), 2471.

18) Y. Tomota, S. Sato and S. Harjo: Tetsu-to-Hagané, 103 (2017), 73 (in Japanese).

19) A. A. Saleh, E. V. Pereloma, B. Clausen, D. W. Brown, C. N. Tomé and A. A. Gazder: Acta Mater., 61 (2013), 5247.

20) H. N. Han and D.-W. Suh: Acta Mater., 51 (2003), 4907.

21) N. Tsuchida: Bull. Iron Steel Inst. Jpn., 21 (2016), 389 (in Japanese).

22) O. Matsumura, Y. Sakuma and H. Takechi: Scr. Mater., 21 (1987), 1301.

23) N. Tsuchida, Y. Morimoto, T. Tonan, Y. Shibata, K. Fukaura and R. Ueji: ISIJ Int., 51 (2011), 124.

24) N. Tsuchida, Y. Yamaguchi, Y. Morimoto, T. Tonan, Y. Takagi and R. Ueji: ISIJ Int., 53 (2013), 1886

25) N. Tsuji, N. Kamikawa, R. Ueji, N. Takata, H. Koyama and D. Terada: ISIJ Int., 48 (2008), 1114.

26) A. Perlade, O. Bouaziz and Q. Furnémont: Mater. Sci. Eng. A, 356 (2003), 145.

27) N. Tsuchida and Y. Tomota: Mater. Sci. Eng. A, 285 (2000), 345. 